\title{
EXERCÍCIOS GRAMATICAIS NO ENSINO \\ DE PAISAGISMO - EXPERIÊNCIAS DIDÁTICAS \\ EM DIFERENTES CONTEXTOS: UFU/UBERLÂNDIA \\ E UNIFOR/FORTALEZA
}

\author{
GRAMMATICAL EXERCISES IN LANDSCAPE ARCHITECTURE TEACHING \\ DIDACTIC EXPERIENCES IN DIFFERENT CONTEXTS: UFU/UBERLÂNDIA \\ AND UNIFOR/FORTALEZA
}

Glauco de Paula Cocozza*

Fernanda Cláudia Lacerda Rocha**

\section{RESUMO}

Este artigo apresenta alguns exercícios gramaticais aplicados na disciplina de Paisagismo da Universidade Federal de Uberlândia e da Universidade de Fortaleza, apresentando a metodologia aplicada, os temas sugeridos para os exercícios, a sua relação com a ementa da disciplina, os reflexos no aprendizado, e como eles possibilitam uma interpretação dos conceitos e práticas que o paisagismo propicia.

Essa temática não é recente, alguns professores adotam metodologias semelhantes, variando o tema, a articulação com conteúdos ministrados e a forma de abordagens. O objetivo deste trabalho é apresentar como os exercícios são pensados na disciplina, como são executados e de que modo se relacionam ao trabalho final entregue como síntese da disciplina de Paisagismo. Palavras-chave: Exercícios gramaticais. Metodologia de ensino. Paisagismo.

\section{ABSTRACT}

This article presents some grammar exercises applied in the discipline of Landscape Architecture, in Federal University of Uberlândia and University of Fortaleza, presenting the methodology applied, the themes suggested for the exercises, their relationship with the program of course, reflections on learning, and how they enable an interpretation of the concepts and practices that provides landscaping.

This theme is not new, many teachers adopt similar methodologies, changing the subject, given the

* $\quad$ Arquiteto e Urbanista pela Universidade Presbiteriana Mackenzie. Professor adjunto da Faculdade de Arquitetura e Urbanismo e Design da Universidade Federal de Uberlândia (FAUeD/UFU). Doutor em Paisagem e Ambiente pela Faculdade de Arquitetura e Urbanismo da Universidade de São Paulo (FAUUSP). Especialista em ensino de Arquitetura Paisagística (FAUUSP/FUPAM/ABAP/ IFLA/UNESCO). FAUeD/UFU. Avenida João Naves de Ávila, 2.121, Santa Mônica, 38400-902, Uberlândia, MG, Brasil.

glauco_cocozza@yahoo.com.br

** Arquiteta e Urbanista pela Universidade Federal do Ceará (UFC). Professora, pesquisadora, coordenadora do Laboratório da Paisagem da Universidade de Fortaleza (Unifor). Mestre em Geografia pelo Programa de Pós-Graduação em Geografia (PROPGEO) da Universidade Estadual do Ceará (UECE). Mestranda em Arquitetura e Urbanismo pelo Mestrado Interinstitucional em Arquitetura e Urbanismo pela Universidade Presbiteriana Mackenzie MINTER UPM/Unifor. Especialista em Paisagismo pela Pontifícia Universidade Católica do Paraná (PUC-PR) e em ensino de Arquitetura Paisagística (FAUUSP/FUPAM/ABAP/IFLA/UNESCO). Fundação Edson Queiroz, Universidade de Fortaleza (Unifor). Avenida Washington Soares, 1.321, Edson Queiroz, 60811-905, Fortaleza, CE, Brasil.

fernandarocha@unifor.br 
links between content and form of approaches. The aim of this paper is to present how the exercises are thought in the discipline, as they are run and how they relate to the final work delivered as a synthesis of the discipline of Landscape Architecture.

Keywords: Grammatical exercises. Teaching methodology. Landscape Architecture.

\section{INTRODUÇÃO}

A discussão acerca de conteúdos, métodos e referências no ensino de Paisagismo em cursos de Arquitetura e Urbanismo não é uma questão recente, tendo se estruturada a partir do Colóquio sobre Ensino de Arquitetura Paisagística, realizado em 1993, na Faculdade de Arquitetura e Urbanismo da Universidade de São Paulo, sob coordenação do Grupo de Disciplinas Paisagem e Ambiente (GDPA/FAUUSP), quando orientou a realização do I Encontro Nacional de Ensino de Paisagismo em Escolas de Arquitetura e Urbanismo (ENEPEA) na Universidade Federal do Rio de Janeiro (UFRJ), ocorrido em 1994. Desde então, os ENEPEA's transformaram-se no principal fórum da discussão, fomentando reflexões e a troca de experiências na área. (I ENEPEA, 1994).

Entretanto, o ponto de partida para o presente artigo deu-se durante o Programa de Capacitação em Arquitetura Paisagística, especialização lato sensu com 360 horas, promovido pela International Federation of Landscape Architects (IFLA), pela Organização das Nações Unidas para a Educação, a Ciência e a Cultura (UNESCO), pela Fundação para a Pesquisa em Arquitetura e Ambiente (FUPAM), pela Associação Brasileira de Arquitetos Paisagistas (ABAP) e pela Faculdade de Arquitetura e Urbanismo da Universidade de São Paulo (FAUUSP), composta de quatro módulos semestrais e realizada entre 2004 e 2005. (PELLEGRINO, 2006).

Na ocasião, o alinhamento da abordagem teórica à experimentação de exercícios gramaticais como metodologia de ensino no Programa chamou atenção dos docentes presentes e oportunizou a disseminação dessa experiência com o objetivo de facilitar o aprendizado em cursos de graduação em Arquitetura e Urbanismo pelo Brasil.

Exercícios abordando a observação e percepção da paisagem, o diálogo entre arte e paisagismo, e modelagem de terreno, fizeram parte do aprendizado sobre metodologias de ensino daquele Programa. Aliando-se esse aprendizado às condições e estruturas de diferentes Instituições de Ensino Superior (IES), passou-se a utilizar tais exercícios como parte integrante dos planos de ensino da disciplina de Paisagismo nos cursos de Arquitetura e Urbanismo da Universidade Federal de Uberlândia (UFU) e da Universidade de Fortaleza (Unifor)'.

Quase uma década após essa experiência, e através da sistematização de erros e acertos em sua utilização, apresenta-se o relato de parte desse processo acadêmico, com a descrição dos referidos exercícios gramaticais e sua utilização nas atividades da disciplina de Paisagismo, na UFU e na Unifor.

Destaca-se que as IES em questão são, respectivamente, pública (UFU) e privada (Unifor). 


\section{OS EXERCÍCIOS GRAMATICAIS}

Os exercícios gramaticais formam a base das disciplinas de Paisagismo nos cursos de Arquitetura e Urbanismo da UFU e da Unifor, com a compreensão de que tais práticas favorecem a integração dos conteúdos com o conhecimento e o desenvolvimento de novas habilidades dos alunos. (ZABALZA, 2004).

A atual matriz curricular do curso de Arquitetura e Urbanismo da UFU possui carga horária total de 3.600 horas-aula, na qual o conteúdo de Paisagismo está dividido em duas disciplinas: Paisagismo I, no quinto semestre, com caráter mais histórico e conceitual, com projeto na pequena escala, e Paisagismo II, no sexto semestre, com reflexões sobre o espaço livre e a cidade e escala do projeto mais amplas, somando o total de 90 horas-aula. Na primeira, os exercícios são utilizados como importantes ferramentas para conciliar o conteúdo da disciplina com o exercício projetual proposto. Alguns deles são adaptações de exercícios gramaticais trabalhados no Programa, enquanto outros foram elaborados de acordo com a necessidade didática.

No caso da Unifor, a matriz curricular do curso totaliza atualmente 252 créditos ou 4.536 horas-aula. A disciplina de Paisagismo está situada no sétimo semestre, contemplando seis créditos (dois teóricos e quatro práticos), equivalendo a 108 horas-aula concentradas em um semestre. Os exercícios constituem, portanto, a tônica da disciplina, e abrangem desde a apreensão de conceitos e fundamentos, a leitura e análise da paisagem até, especialmente, o desenvolvimento do processo de projeto, como propósito maior. Destaca-se que, anualmente, são abordados diferentes temas, escolhidos em função do contexto, da atualidade de discussões, ou de interesse de pesquisa, normalmente em abrangência de média escala - a praça. (ROCHA, 2009, 2010 e 2011).

Quadro 1 Quadro Comparativo dos Conteúdos e Exercícios Aplicados nas Duas Universidades

\begin{tabular}{|c|c|}
\hline \multicolumn{2}{|c|}{ UFU - UNIVERSIDADE FEDERAL DE UBERLÂNDIA (MG) } \\
\hline Conteúdo & Exercício gramatical \\
\hline Fundamentos do Espaço Livre & Exercício do isopor \\
\hline Metodologia: Conceito, Forma e Função & Exercício da casa \\
\hline Representação e vegetação & $\begin{array}{l}\text { Exercício de escolha de espécies e } \\
\text { representação em paisagismo }\end{array}$ \\
\hline Arte e paisagismo & Exercício da pintura \\
\hline Modelagem e projeto & Exercício da maquete em pequena escala \\
\hline Projeto de paisagismo & Exercício de projeto em pequena escala \\
\hline \multicolumn{2}{|c|}{ Unifor - UNIVERSIDADE DE FORTALEZA (CE) } \\
\hline Conteúdo & Exercício gramatical \\
\hline Conceitos e Fundamentos & Diagrama conceitual \\
\hline Representação e identificação de vegetação & Modelos arquitetônicos de árvores \\
\hline Leitura e apreensão da paisagem & Inventário, análise e diagnóstico \\
\hline
\end{tabular}




\begin{tabular}{l|c}
\hline \multirow{4}{*}{ Projeto do Espaço Livre } & $\begin{array}{c}\text { Zoneamento, conceito e } \\
\text { programa de necessidades }\end{array}$ \\
\cline { 2 - 2 } & Plano de massa \\
\cline { 2 - 2 } & Estudo preliminar \\
\hline
\end{tabular}

Fonte: Glauco de Paula Coccoza e Fernanda Cláudia Lacerda Rocha - 2012.

\subsection{APLICAÇÕES NA UNIVERSIDADE DE UBERLÂNDIA}

A seguir, vejamos a sequência de exercícios gramaticais utilizados na disciplina de Paisagismo I da UFU.

No primeiro exercício, objetiva-se transmitir ao aluno o significado do projeto do espaço livre, objeto central do paisagismo. O exercício, denominado Exercício de Maquete em Isopor, usa uma placa de isopor de $1 \mathrm{~cm}$. $O$ aluno divide a mesma ao meio e forma a base na qual fará o trabalho, utilizando materiais para fazer a vegetação, como palitos de dente, bolas de isopor, palha de aço ou algum tipo de bucha. Na primeira parte do exercício, é pedido ao aluno que projete uma casa rapidamente, após dado um programa mínimo, que geralmente consiste de sala, cozinha, dois quartos e um banheiro. A partir do esboço inicial, cada estudante deverá construir uma maquete da proposta, utilizando paredes feitas com a outra metade da placa de isopor. A intenção desse exercício é fazer com que o aluno projete a casa não imaginando a segunda parte do exercício. A maioria acredita que fará um jardim no exterior da casa, por isso, muitos fazem projetos pensando na parte externa ao edifício. Os alunos finalizam a maquete (somente paredes e aberturas) e, após essa etapa, devem desenhar o que estão vendo, tanto em planta como em perspectiva². Não há escala definida (figura 1).

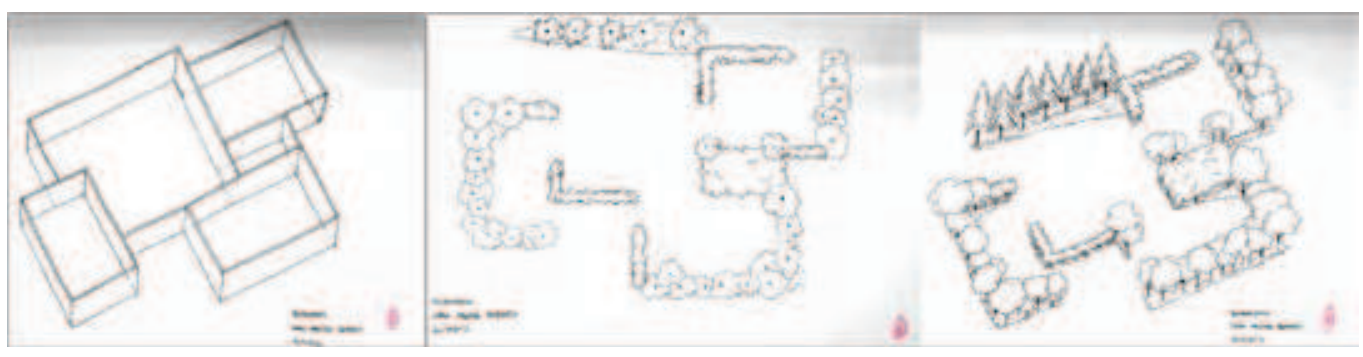

Figura 1 Desenhos feitos a partir do exercício do isopor, com espaços criados através do pensamento projetual do edifício.

Fonte: Disciplina de Paisagismo I da FAUeD - 2011.

A segunda parte do trabalho consiste em substituir as paredes por espécies vegetais, ou seja, a mesma espacialidade criada no projeto da casa deverá ser a espacialidade do paisagismo. Nesse momento, o aluno se depara com alguns questionamentos: escalas, forma das árvores, tipos de espaço.

interessante é observar como se surpreendem com o resultado, que, provavel-

2 Nesse exercício não há escala definida, porém costuma-se utilizar a escala de 1:100. 
mente, não seria o mesmo se fosse pedido para construir um jardim na mesma base. objetivo desse trabalho é fazer com que o estudante, acostumado com o processo de pensar o espaço construído, comece a pensar o projeto do espaço livre pelo mesmo processo projetual.

No final do exercício, ele faz uma planta do projeto paisagístico e uma perspectiva isométrica para comparar com o projeto edificado. Nessa etapa, não há preocupação com a definição de espécies, com a função do espaço e com a representação, mas com as espacialidades criadas pelo elemento vegetal através do processo projetual. Esse exercício inicial é um estímulo para que o estudante se solte para os posteriores trabalhos.

No segundo trabalho, o aluno deve trazer algum projeto de residência feito durante o curso, seja nas disciplinas de projeto ou em outras. Após uma aula teórica sobre conceito e forma ${ }^{3}$, em que diferentes propostas de desenho e organização do espaço livre são apresentadas, ele deve utilizar o projeto da residência para esboçar o conceito do projeto. Inicialmente, é feita uma discussão sobre as casas e como elas se relacionam com o espaço livre. Geralmente, percebe-se que este é somente algo que sobra no terreno, e que é pintado de verde para dar a conotação de um gramado. Esse primeiro ensaio faz com que o aluno perceba a importância estrutural do paisagismo no projeto arquitetônico.

A seguir, o aluno começa e esboçar ambientes que possam ser inseridos no projeto, criando, assim, o programa: área de lazer, estar, lago, piscina. Tais espaços são caracterizados por um esquema de manchas no qual se delimita cada área, e, através de setas, indicam-se possíveis articulações e caminhos que esses ambientes terão. A partir dessa definição, que implica a funcionalidade do projeto, o aluno escolhe, através das possibilidades conceituais apresentadas na aula teórica, um desenho que represente o conceito do projeto, seja através de formas mais ortogonais ou mais naturais (figura 2).

O objetivo central desse trabalho é mostrar ao aluno como se dá a relação entre o edifício e o espaço livre, e como, metodologicamente, forma e função apresentam importante articulação no momento de definir qual o conceito do projeto. Outro objetivo é mostrar a importância do paisagismo na definição do partido arquitetônico, não somente como moldura e preenchimento espacial, mas enquanto condicionante da organização de todo o projeto. Nesse exercício, o estudo começa a deparar-se com a questão da escala, da organização do espaço, da função, e com a representação gráfica do projeto.

3 O Exercício se baseia no livro From concept to form in landscape design, de Grant W. Reid 


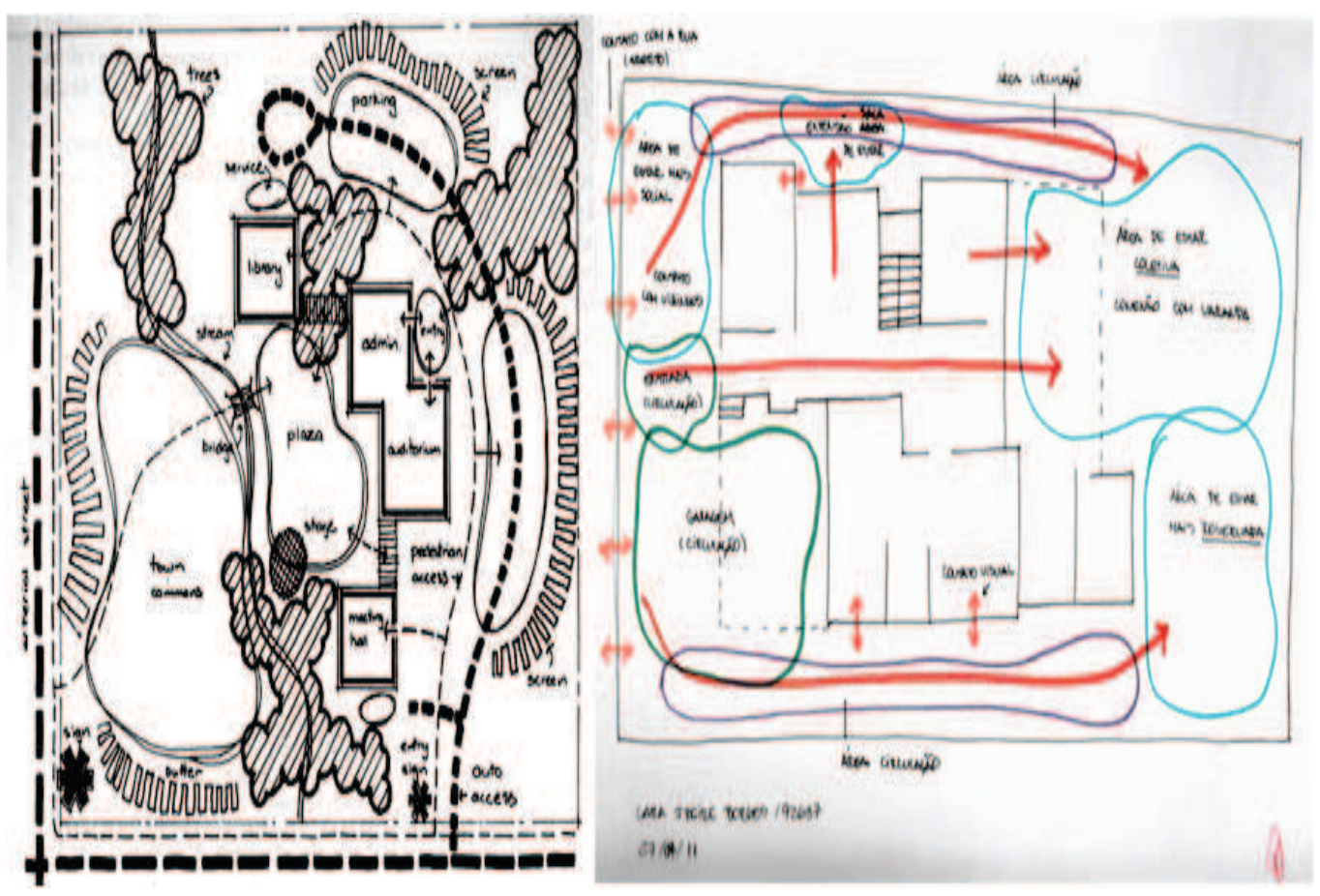

Figura 2 Esboço feito por aluno utilizando projeto residencial baseado em esquema de Reid (2007). Fonte: Disciplina de Paisagismo I da FAUeD - 2011.

Nessa crescente evolutiva do curso, o terceiro exercício possui o objetivo de propiciar ao aluno pesquisar, conhecer e representar as espécies que poderão ser utilizadas em um projeto. Após aulas teóricas sobre a vegetação utilizada em projetos de paisagismo e sobre representação, cada aluno deve pesquisar algumas espécies na literatura especializada, verificando suas principais características - tipo, floração, porte, incidência - e, posteriormente, representá-las em duas folhas A3: a primeira em planta e a segunda em corte. Assim, o aluno começa a compreender a arquitetura das espécies, texturas, cores, proporção, porte e outros aspectos que servirão para definir o conceito e a forma de representar o projeto (figura 3).

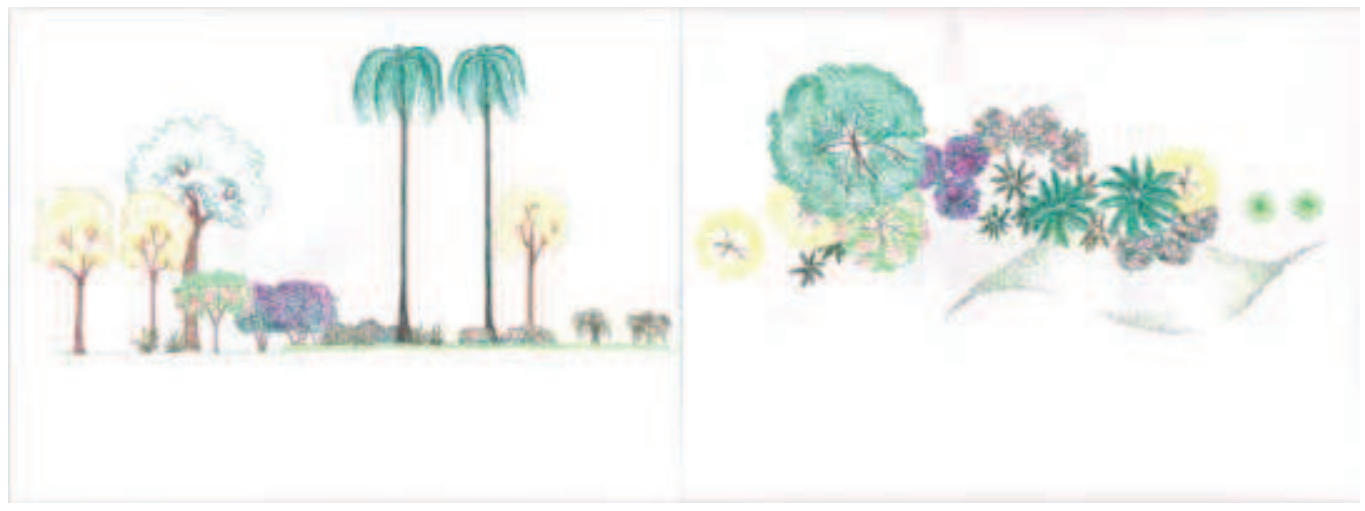

Figura 3 Desenhos de representação das espécies estudadas pelo aluno.

Fonte: Disciplina de Paisagismo I da FAUeD - 2012. 
O quarto exercício proposto alia arte e paisagem. Cada aluno deve escolher uma pintura abstrata e trazê-la impressa em uma folha no formato A4. A partir dessa pintura, deverá criar um jardim com as mesmas características de composição. A liberdade propiciada pela obra de arte faz com que o estudante não fique preso a um programa e nem a um conceito, tomando para o projeto a condição plástica da obra para a composição de um espaço com as mais diferentes características, com cursos d'água, lagos, piscinas, coberturas, caminhos, canteiros (figura 4).

Nesse ponto da disciplina de Paisagismo I, foram propostos exercícios que permitem liberdade de criação e propostas mais técnicas, mais limitadoras, porém não menos eficientes para o entendimento do processo projetual. $\bigcirc$ exercício sobre a obra de arte ganhou, nos últimos anos, condicionantes que estão se moldando para o melhor aprendizado, como a delimitação de uma área para o projeto, forçando o aluno a trabalhar com uma escala predefinida e, assim, aplicar as espécies escolhidas no exercício 3 para definir seu espaço. A ideia de sobreposição de exercícios é algo importante para o aluno perceber a conexão entre os objetivos propostos e como os projetos podem resultar desse processo.

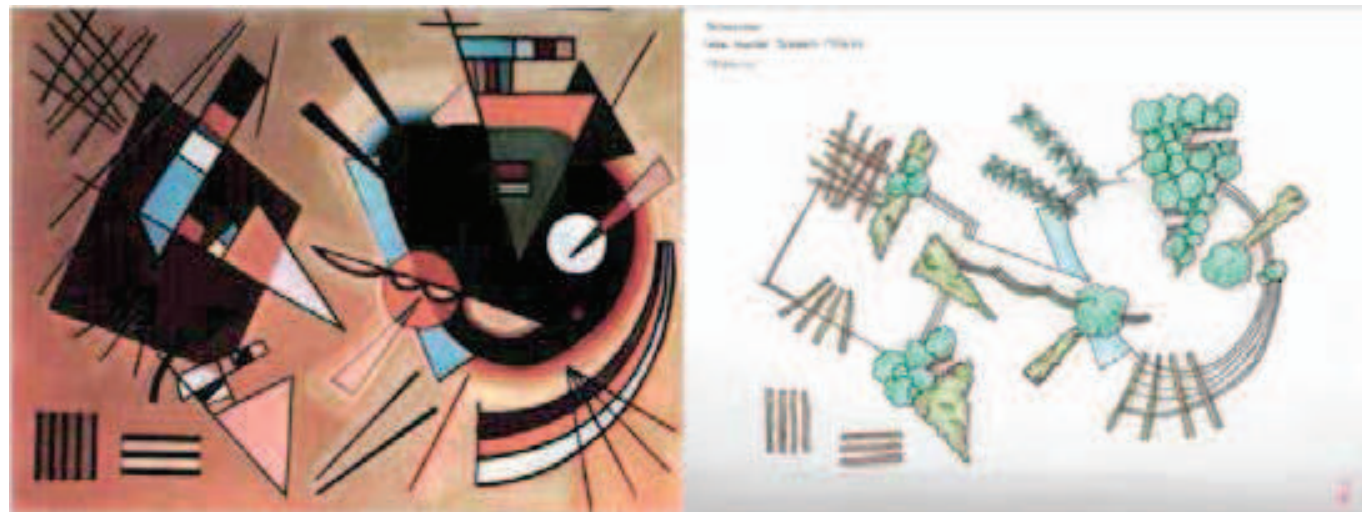

Figura 4 Black and Violet (1923), de Wassily Kandinsky. Obra escolhida pelo aluno para o desenvolvimento do exercício. Na figura, vê-se a obra e sua materialidade em projeto de paisagismo.

Fonte: Disciplina de Paisagismo I da FAUeD - 2011.

Uma observação que vale ressaltar é a superação pelos alunos em relação a dificuldades de espacialização através dos exercícios. Se fosse solicitada uma espacialização sem os condicionantes exigidos, talvez não houvesse o mesmo resultado, pois a dificuldade de romper com o papel em branco ainda ocorre em algumas ocasiões.

Em alguns semestres, após essa etapa, já partiríamos para o exercício final da residência, porém, nesse último uma nova proposta surgiu: a de fazer outro exercício de maquete, utilizando o exercício da pintura. Como o aluno trabalhou com escala e com a vegetação escolhida, deverá agora construir uma maquete desse exercício e, assim, modelar o espaço através da vegetação - com suas principais características. A maquete é um elemento de estudo essencial para que a espacialidade criada pela vegetação tome outra dimensão no projeto. Nesse momento, o aluno 
pode voltar, corrigir aspectos que o desenho não apresentava e incorporar novos elementos ao projeto.

O exercício final é a articulação entre tais exercícios e a necessidade de projetação exigida e essencial para a disciplina de Paisagismo I. Como se trata do primeiro contato com o tema, o objeto de intervenção se dá na escala residencial. Observa-se que, mesmo não seguindo os exercícios passo a passo, o objetivo de cada um deles acaba se incorporando no resultado final do projeto (figura 5).

Nesse projeto final, algumas experiências já foram realizadas, a partir de uma residência pronta ou com o aluno escolhendo a residência, ou até projetando uma residência. No último caso, uma característica marca o projeto: a conexão maior entre o espaço livre e o construído - característica essencial para a formação generalista de arquiteto e urbanista, pois poderá exercitar duas habilidades em um único exercício. No exercício final, exige-se o conceito do projeto: exercício 2; a definição das espécies e dos materiais: exercício 3; maquete do projeto: exercício 5, evidenciando o papel de inter-relação entre os demais exercícios.

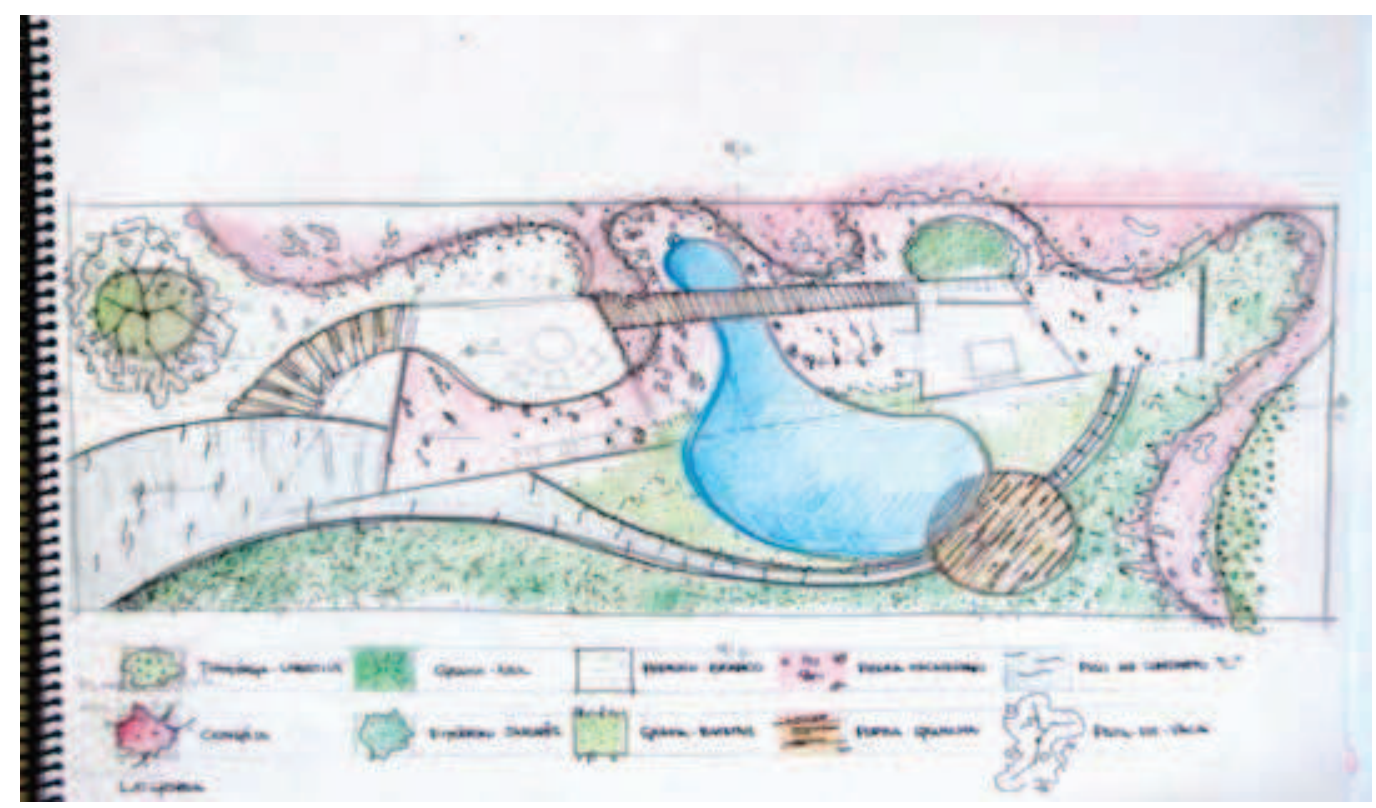

Figura 5 Trabalho Final do curso de Paisagismo I. Fonte: Disciplina de Paisagismo I da FAUeD - 2011.

\subsection{APLICAÇÕES NA UNIVERSIDADE DE FORTALEZA}

A sequência de exercícios gramaticais aplicados no desenvolvimento da disciplina de Paisagismo durante o semestre, na Unifor, contempla alguns que selecionamos a seguir.

O desenvolvimento de diagramas conceituais é uma prática que ocorre em pelo menos três momentos, logo nas primeiras semanas de aula, e objetiva trabalhar a apreensão dos conceitos discutidos - tais como Paisagismo, Paisagem, Arquitetura 
Paisagística - a partir de desenhos. Os exercícios assim se denominam por exigirem do aluno uma elaboração com justificativa para a construção do conceito e de sua representação. Para elucidar o que se entende por conceito e qual sua função no projeto paisagístico, são apresentados exemplos de projetos com a explicitação de conceitos no seu desenvolvimento, junto aos depoimentos de arquitetos contidos em CD-ROM produzido por ocasião do V ENEPEA, em 2000, no Rio de Janeiro. O trabalho se desenvolve em sala ou como tarefa de casa, dependendo da disponibilidade de tempo, e é apresentado em papel sulfite formato $A 3$, deixando livres as formas de expressão do aluno (figura 6).

No exercício de modelos arquitetônicos de árvores, a representação e a identificação de espécies normalmente acontecem a partir do lugar onde será desenvolvida a proposta de projeto, para que se ganhe tempo também com relação ao inventário do local. Após a apresentação do conteúdo teórico correspondente, e a partir da relação das espécies vegetais existentes por nomes populares, é solicitada sua identificação por tipologias e representação gráfica em papel sulfite A3, com desenhos à mão livre em planta e vista contendo referência humana, com técnica à escolha do aluno (figura 7).

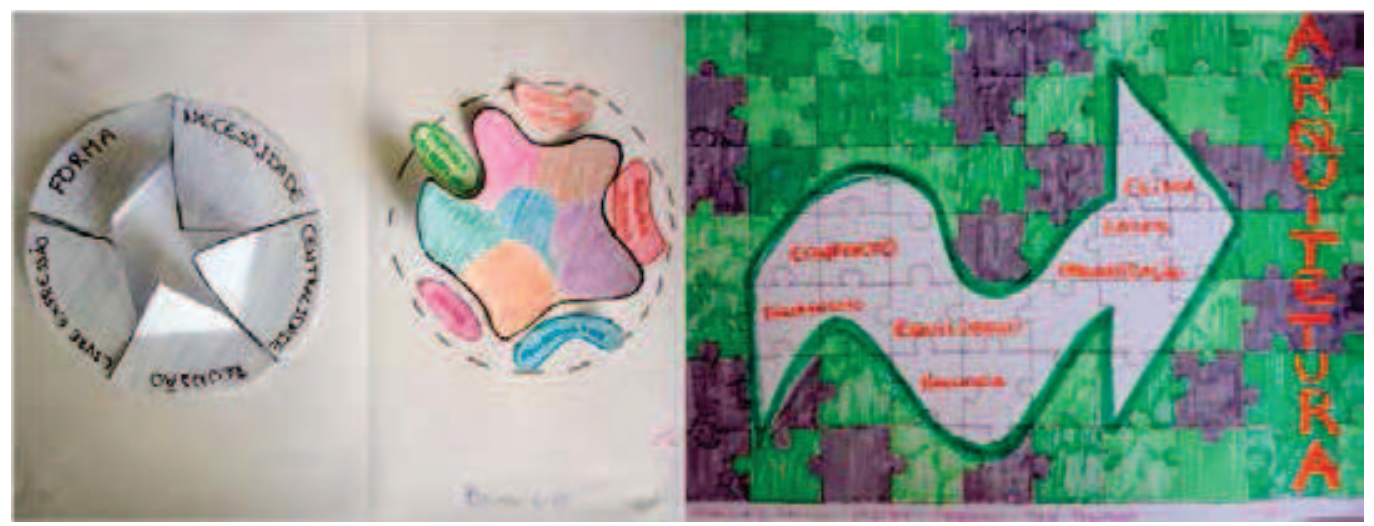

Figura 6 Diagramas conceituais de duas alunas em exercícios distintos. Fonte: Disciplina de Paisagismo da Unifor $-1^{\circ}$ sem. 2010.

No exercício de modelos arquitetônicos de árvores, a representação e a identificação de espécies normalmente acontecem a partir do lugar onde será desenvolvida a proposta de projeto, para que se ganhe tempo também com relação ao inventário do local. Após a apresentação do conteúdo teórico correspondente, e a partir da relação das espécies vegetais existentes por nomes populares, é solicitada sua identificação por tipologias e representação gráfica em papel sulfite A3, com desenhos à mão livre em planta e vista contendo referência humana, com técnica à escolha do aluno (figura 7).

Faz parte do exercício a correta identificação botânica e para facilitar o contato do aluno com o elemento vegetal são feitas, anteriormente, visitas de identificação ao campus e oficina de plantio na Casa de Vegetação, um dos laboratórios específicos do curso. 


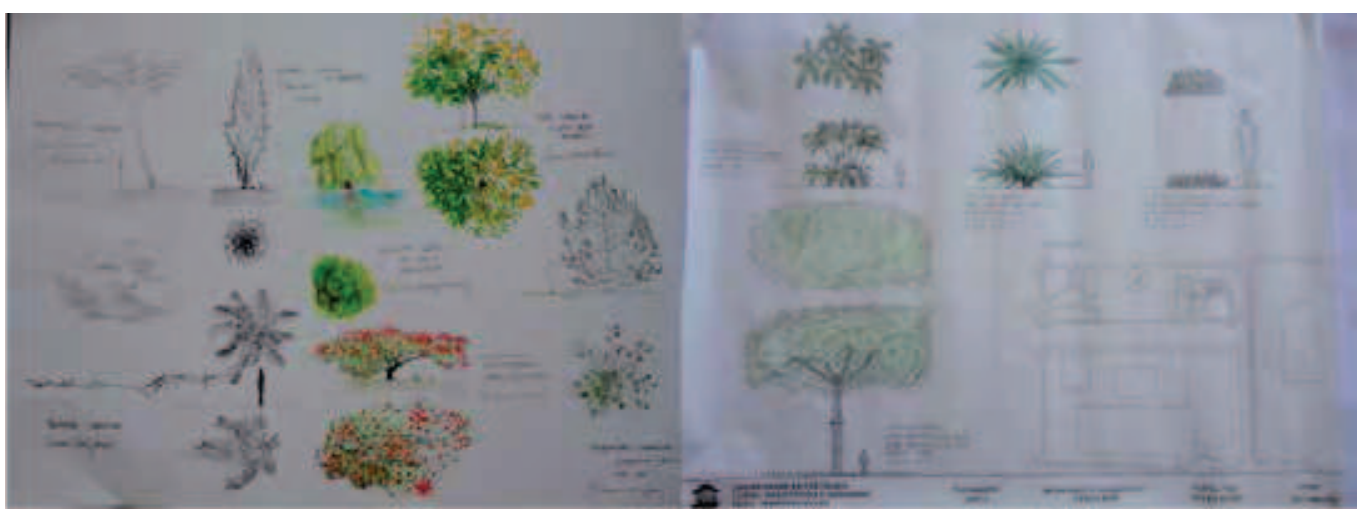

Figura 7 Exercícios de representação e identificação de elementos vegetais. Fonte: Disciplina de Paisagismo da Unifor - $2^{\circ}$ sem. 2010.

Para o inventário, análise e diagnóstico são solicitados exercícios baseados em Kevin Lynch e Gordon Cullen, a leitura e a apreensão da paisagem onde ocorrerá a intervenção proposta. Nesse exercício, a intenção é de sensibilizar os alunos para a percepção das condicionantes do local, identificando problemas e potencialidades a serem trabalhadas na proposta. É possível o uso de computador desde que haja materiais complementados com croquis à mão, visando ao desenvolvimento das habilidades de desenho à mão livre (figura 8).
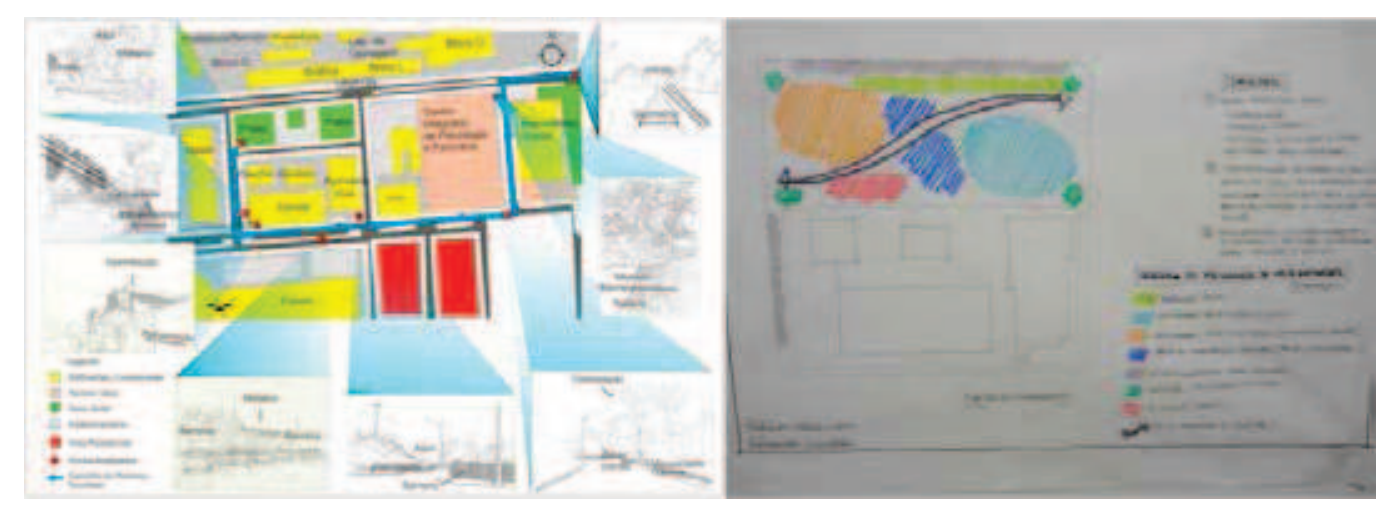

Figura 8 Exercícios de leitura e apreensão da paisagem.

Fonte: Disciplina de Paisagismo da Unifor - $1^{\circ}$ sem. 2011.

No desenvolvimento da ação projetual propriamente dita, utilizam-se diferentes exercícios, executados sequencialmente. Inicialmente, solicita-se o zoneamento, em conjunto com a definição conceitual da proposta e a elaboração do programa de necessidades a ser implantado, partindo-se do diagnóstico anteriormente executado (figura 8). Em seguida, elabora-se, em conjunto, o plano de massa (figura 9) e o modelo volumétrico processual (figura 10), que irão se complementando mutuamente, apoiando as decisões de estruturação do espaço até a proposta final de projeto. 
As três etapas de desenvolvimento de projeto ocorrem em ateliê, sendo mediadas pelo professor da disciplina. Os desenhos, plantas, cortes e detalhes em croquis são elaborados obrigatoriamente à mão, em papel manteiga formato $A 2$ ou $A 1$, dependendo das dimensões da área em questão. Além da proposta do local em estudo, deve-se atentar para sua relação com o entorno próximo, elaborando-se, ao menos, diretrizes de intervenções urbanas na vizinhança. $\bigcirc$ modelo volumétrico que, inicialmente, se presta também ao inventário, é continuamente modificado até dar origem à concepção final. Por isso, não se exige um trabalho minucioso de acabamento do mesmo, já que os objetivos são a compreensão da estruturação do espaço livre, o reconhecimento de escalas e o domínio volumétrico do conjunto. Na confecção do modelo, são utilizados isopor, papéis coloridos, palitos e fibra de limpeza para a confecção dos elementos vegetais.

Como consideração comum aos exercícios gramaticais expostos, destaca-se que todos devem ser apresentados e discutidos em grupo, favorecendo a troca de informações e o debate construtivo de ideias. Esses seminários também compõem a avaliação de cada exercício e ajudam o aluno a posicionar-se na defesa de suas propostas em público.

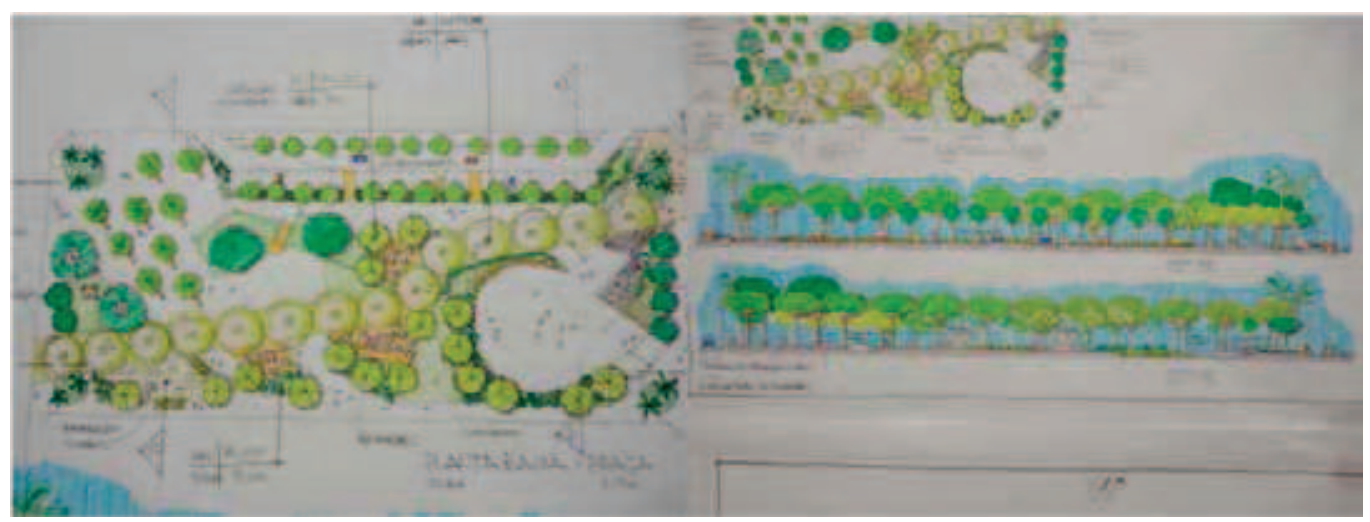

Figura 9 Estudo para plano de massa em planta e cortes proposto por aluno. Fonte: Disciplina de Paisagismo da Unifor $-1^{\circ}$ sem. 2010.

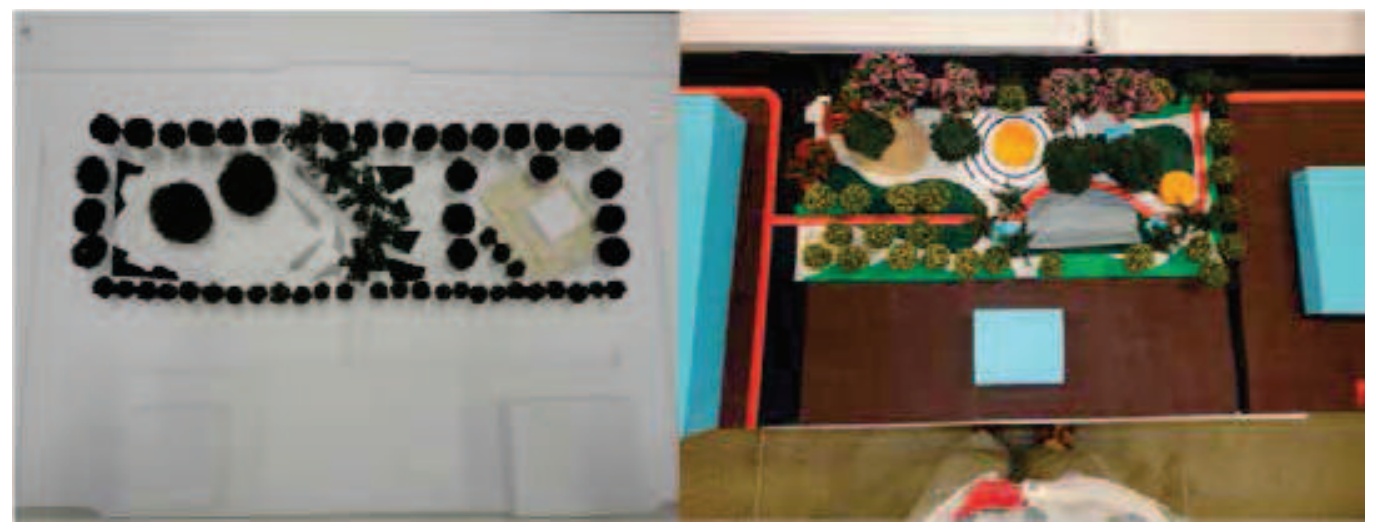

Figura 10 Estágios inicial e final de diferentes modelos volumétricos ao longo do processo projetual. Fonte: Disciplina de Paisagismo da Unifor - $1^{\circ} \mathrm{sem} .2011$. 


\section{CONSIDERAÇÕES FINAIS}

A partir da troca de experiências entre dois professores em distintas universidades brasileiras, com realidades acadêmicas e estruturais diferentes, considerou-se a oportunidade de descrever e comparar os exercícios gramaticais utilizados na disciplina Paisagismo, no curso de Arquitetura e Urbanismo dessas instituições, considerando seus objetivos e resultados.

Alguns professores adotam práticas semelhantes, e outros adotam experimentações diversas, possibilitando ao aluno novas oportunidades de experimentação espacial. Um ponto nos parece ser uma preocupação comum: como estimular o aluno à busca do conhecimento para que esteja apto a desenvolver o projeto de paisagismo com tão pouca carga horária e com tão vasto conteúdo a ser desenvolvido?

Sem adentrar questões de outra ordem sobre o ensino de Paisagismo em cursos de graduação em Arquitetura e Urbanismo, parece-nos que a dificuldade de conciliar tempo e conteúdo leva alguns professores a desenvolver ou adaptar metodologias que viabilizam a formação do aluno de modo mais dinâmico e participativo. Nesse aspecto, este trabalho pretende contribuir com a discussão metodológica sobre o ensino de Paisagismo fazendo um paralelo entre as circunstâncias destas IES.

\section{REFERÊNCIAS BIBLIOGRÁFICAS}

ABBUD, Benedito. Criando paisagens. São Paulo: Senac, 2006. 207 p.

FARAH, Ivete; SCHLEE, Mônica Bahia; TARDIN, Raquel. Arquitetura paisagística contemporânea no Brasil. São Paulo: Senac, 2010. 232 p.

McLEOD, Virginia. El detalle em el paisajismo contemporáneo. Barcelona: Blume Naturart, 2008.192 p.

PELLEGRINO, Paulo Renato. O programa de capacitação em arquitetura paisagística. Pós. Revista do Programa de Pós-Graduação em Arquitetura e Urbanismo. São Paulo: FAUUSP, n. 19, 2006, p. 212-219.

REID, Grant W. From concept to form in landscape design. Universidade da Califórnia, John Wiley \& Sons, 2007. 256 p.

ROCHA, Fernanda Claudia Lacerda. Paisagismo, um campo interdisciplinar de ensino e aprendizado: desafios e potencialidades. In: ENCONTRO DE PRÁTICAS DOCENTES. Fortaleza: Fundação Edson Queiroz, 2009, p. $1-5$.

O uso de diagramas conceituais como instrumento de aprendizagem em Arquitetura e Urbanismo. In: ENCONTRO DE PRÁTICAS DOCENTES, 2, 2010, Fortaleza: Fundação Edson Queiroz.

Quid pro quod: modelo volumétrico processual e estruturação do espaço livre. In: ENCONTRO DE PRÁTICAS DOCENTES, 3, 2011 , Fortaleza: Fundação Edson Queiroz, p. 1-6.

TABACOW, José. Arte e paisagem. São Paulo: Studio Nobel, 2004. 224 p.

ZABALZA, Miguel A. O ensino universitário: seu cenário e seus protagonistas. Porto Alegre: Artmed, 2004. 239 p.

\section{AGRADECIMENTOS}

Agradecemos o apoio dispensado às nossas atividades, dentro e fora da sala de aula, pelas administrações superiores de ambas as IES, UFU e Unifor, assim como dos respectivos Coordenadores de Curso e Diretores de Centro. 
Exercícios Gramaticais no Ensino de Paisagismo - Experiências Didáticas em Diferentes Contextos: UFU/Uberlândia e UNIFOR/Fortaleza

Aos demais professores com quem trocamos experiências didático-pedagógicas ao longo deste percurso, por suas observações e questionamentos e, por último - mas na verdade a razão primeira da prática docente -, aos alunos que temos a felicidade de encontrar no decorrer deste processo e com quem muito aprendemos.

À Fundação Cearense de Apoio ao Desenvolvimento Científico e Tecnológico (Funcap). 
Glauco de Paula Cocozza e Fernanda Cláudia Lacerda Rocha 